\title{
Attitudes and Behavioural Intentions of Typically Developing Adolescents towards a Hypothetical Peer with Asperger Syndrome
}

\author{
Eleni Fleva, ${ }^{1, *}$ \\ ${ }^{1}$ University of Reading, UK \\ *Correspondence: Language Development Lab, Department of Theoretical and Applied Linguistics, School of \\ English, Faculty of Philosophy, 541-24, Aristotle University, Thessaloniki, Greece. E-mail: \\ eleni.fleva@googlemail.com
}

Received: November 10, 2014

Accepted: December 1, 2014 Online Published: December 15, 2014

doi:10.5430/wje.v4n6p54

URL: http://dx.doi.org/10.5430/wje.v4n6p54

\begin{abstract}
This study examines the attitudes and the behavioural intentions of typically developing (TD) adolescents towards a hypothetical peer with Asperger syndrome (AS). Participants (N=179, $M$ age=13.7 years) viewed two Powerpoint presentations one of a TD male target and one of a male target with AS. The target with AS was introduced either with descriptive or combined information delivered either by a hypothetical friend or by a hypothetical teacher. Attitudes and behavioural intentions were assessed by the administration of the Shared Activities Questionnaire and the Adjective Checklist. Results yielded that participants were more positive towards the TD target than towards the target with AS. Regarding the target with AS, there was no significant overall advantage of either information type whereas the friend rather than the teacher source triggered more positive responses. Limitations and suggestions for future research are discussed.
\end{abstract}

Keywords: Asperger syndrome; attitudes; intentions; information; source

\section{Introduction}

Asperger syndrome (AS) can be defined as a "severe developmental disorder characterised by major difficulties in social interaction and restricted and unusual patterns of interest and behaviours" (Klin \& Volkmar, 1995, p. 1). Konza (2005) pointed out that the general demeanor of students with AS can easily differentiate them from their peers. For instance, students with AS in comparison to typically developing (TD) students often appear socially naive and not able to understand jokes (Konza, 2005). Additionally, they often exhibit a desire to retain routines or rituals (Asperger, 1991; Attwood, 2003; Linn \& Myles, 2004; Williams, 2001) while at the same time they might display a preoccupation with specific interests (Lamarine, 2001). That is, for people with AS it is difficult to pay attention to topics out of the sphere of their own interests (Ehlers \& Gillberg, 1994) which can eliminate their opportunities to share enjoyable times with others. A number of other characteristics associated with AS can further hamper peer interaction. For instance, an inability to grasp nonverbal communication cues (Lamarine, 2001), sensory sensitivities (Attwood, 2003; Safran, 2002) or intense discomfort in being in physical proximity with others (Konza, 2005). These features along with lack of social skills often place children with AS to "stand out" from their peers and thus to experience not only isolation but often adverse behaviour (Shtayermman, 2007).

According to Attwood (2006), students with AS perfectly fit the profile of being potential targets of bullying as they appear to be shy, quiet-loners with a limited or no peer network. Wainscot, Naylor, Sutcliffe, Tantam and Williams (2008) interviewed 5-11 year old children with AS about their bullying experiences at school and compared their responses to a control group of same-age TD children. The results showed that children with AS experienced greater peer victimization compared to controls and this was expressed in the form of either verbal, physical or social bullying. Humphrey and Lewis (2008) asked 20 students (age range 11-17 years) with AS to keep a diary about their school experiences related to their interaction with their peers. What was worrying was that all of the pupils reported being regularly victimized by their peers by name-calling means. Some of the pupils also reported to experience physical violence as well: "...[male pupil] is very nasty and keeps punching me... whenever he sees me." (p. 34) whereas worrying enough one of the student drew a picture depicted his death while another student drew himself 
being at class with other pupils pointed and laughing at him. As a result of negative behaviours, children with AS often report great social exclusion (Kasari, Locke, Gulsrud \& Rotheram-Fuller, 2011) and few social networks (Bauminger, Solomon, Aviezer, Heung, Brown \& Rogers, 2008) compared to TD peers. This appears to be more salient during adolescence (Church, Alianski \& Amanullah, 2000). A 13 year-old boy with AS described that the same students that he shared common interests with during childhood they now "act completely differently...they're like completely different people" (Marks, Schrader, Longaker \& Levine, 2000, p. 8). It appears that during adolescence TD children's interests are rapidly changing and they focus more on interpersonal relationships, while children with AS may still exhibit a preference for sameness or unusual interests (Adreon \& Stella, 2001). The present work focus on examining attitudes and behavioural intentions of TD students towards peers with AS during adolescence period as it appears that there is a need to focus on this developmental stage.

One way to change attitudes towards peers with disabilities is by providing educational messages. Nabors and Larson (2002) introduced two types of information to improve children's attitudes towards their peers with disabilities: descriptive and explanatory information. Descriptive information highlights similarities between the audience and the child with the disability. Descriptive information is based on the principles of cognitive consistency theories (Heider, 1958) and assumes that perceived similarity enhances attraction and likeability if the other person is viewed as being similar to the perceiver. Explanatory information, on the other hand, informs participants about the child's disability and also explains to them what the condition is. For example, participants that are introduced to a child with autism are told what autism is and receive a simple explanation of his/her atypical behaviour (Campbell, Ferguson, Herzinger, Jackson \& Marino, 2004). Explanatory information is based on attribution theory proposed by Weiner (1980) which describes the tendency to question "why" a particular behaviour occurs (e.g., "why is the new kid in the class rocking back and forth?") (Campbell, 2006, p. 260). The answer to this question determines the direction of the perceiver's behaviour towards that individual (Taylor, Peplau \& Sears, 2003). The lower the degree of control and responsibility that the individual is perceived to have for their behaviour, the more likely is it that the perceiver will act prosocially (Sigelman, 1991). In contrast, the higher the degree of perceived responsibility, more anger and less sympathy will be observed (Campbell, 2006). Provision of explanatory information aims to reduce the degree of responsibility attributed to children (or adults) with disabilities by correcting misconceptions about the caused and controllability of the condition. Studies have shown that participants hold more positive attitudes towards people whose physical (Jones, Farina, Hastorf, Marcus, Miller \& Scott, 1984) mental (Weiner, Perry \& Magnusson, 1988) or intellectual (Panek \& Jungers, 2008) impairments are attributed to uncontrollable than to controllable causes.

Both explanatory and descriptive information as well as the combination of this two information types (combined information) have been applied as a method to improve children's attitudes and behavioural intentions towards hypothetical peers with autism. However, the literature indicates inconsistent results. For example, Swaim and Morgan (2001) found that an educational message about autism had no effect on young children's attitudes and behavioural intentions towards a hypothetical peer with autism. In contrast, Campbell et al (2004) found an effect of explanatory information but with small magnitude. Similarly, Campbell (2007) found an effect of explanatory information but in this study the gender ratio of participants was unbalanced.

Morton and Campbell (2008) examined whether combined information resulted in different effects on attitudes and behavioural intentions towards a hypothetical peer with autism when manipulated the person who delivers the information. This study revealed that young children (3rd graders) were influenced by combined information when it was delivered by parental sources while older children (4th and 5th graders) were influenced by more credible and authoritative sources (a teacher and a doctor). Thus, it appears that different people differently influence children's attitudes towards a peer with autism depending on the children's developmental stage.

\subsection{Purpose of the Study}

The broad aim of this work is to examine the attitudes and the behavioural intentions of TD adolescents towards a hypothetical peer with AS. This is because based on attribution theory children with AS compared to children with autism might be perceived as more responsible for their atypical behaviour because they have better language skills and are often characterised by good academic achievements (Lamarine, 2001). Thus, this mismatch between typical development and atypical behaviour might increase the degree of responsibility attributed to them. Also, this study examines the attitudes and intentions of young adolescents rather than children. This is because, attitudes towards peers with disabilities are often more negative during adolescence than childhood and the same appears to be true towards peers with AS (Marks et al., 2000).

This work further aims to re-examine the impact of descriptive and combined information in an attempt to introduce 
this method as a potential intervention to ameliorate young adolescent's attitudes and behavioural intentions towards their peers with AS. Finally, this study aims to examine the efficacy of information when provided either by the target's hypothetical friend and teacher. A teacher source was chosen because although Morton and Campbell (2008) recruited younger participants than those recruited here, their findings showed that the older the children the more they were affected by authoritative sources. A friend source was chosen because participants here are young adolescents and thus it is expected to be influenced by similar others. Thus, information delivered by a similar other can increase likeability which in turn can have a positive effect on attitudes.

This study aims to address the following research questions:

a) Do typically developing adolescents show less positive attitudes and behavioural intentions towards a hypothetical peer with AS versus a TD peer?

b) When examining attitudes towards the peer with AS, does descriptive or combined information give rise to more positive attitudes and intentions?

c) When examining attitudes towards the peer with AS, is information more effective when presented by a teacher or by a friend?

d) Are younger compared to older participant's attitudes and intentions more positive towards the target with AS?

e) Are the attitudes and behavioural intentions of males or females more positive towards the target with AS?

\section{Method}

\subsection{Research Design}

The study had a mixed design with 3 between-subject factors (Information type: descriptive vs. combined, Information source: friend vs. teacher, Year: Year 7 vs. Year 10) and one within-subject factor (the AS vs. the TD target). Gender of participants was also included in the analysis. The main dependent variables of the study were the attitudes and the behavioural intentions towards the TD and the AS target. Participants were randomly allocated to one of the following four experimental conditions in a $2 \times 2$ within-subjects design:

(1) A hypothetical teacher will provide descriptive information for both the TD target and the target with AS

(2) A hypothetical teacher will provide descriptive information for the TD target and combined information about the target with AS

(3) A hypothetical friend will provide descriptive information for both the TD target and the target with AS

(4) A hypothetical friend will provide descriptive information for the TD target and combined information about the target with AS

\subsection{Participants}

Participants were 179 (age range: 10-16 years, mean age $=13.7)$ male $(\mathrm{N}=97)$ and female $(\mathrm{N}=82)$ students. Participants either attended Year $7(\mathrm{~N}=91$, mean age $=12.3)$ or Year $10(\mathrm{~N}=88$, mean age $=15.3)$. Children were recruited through a parental consent form sent home from school along with information about the study. Information for children was also sent home from school. In order to participate, students were asked to give written consent before the study began. Only students who signed consent forms and whose parents had signed consent forms participated in the study. Participants were tested as a group in classroom settings and whole classes were randomly allocated to a condition. In order to assess typically developing student's attitudes and behavioural intentions towards peers with AS but also because of ethical reasons only classes that did not include students with AS were chosen.

The school were the data were collected from is a large state mainstream secondary school, which received a rating of "good" by Ofsted in 2010, and which became an Academy school in 2011. Consistent with the town's population, the school has a very small proportion of pupils from different ethnic minorities. The school has a reputation for excellent special needs support, and as a result has a higher than average number of children with Statements of Educational Need. A larger than average number of children with AS attend this school, and the school ethos is welcoming and supportive.

\subsection{Measures}

All participants were administered with the Shared Activities Questionnaire (SAQ) (Morgan, Walker, Bieberich \& Bell, 1996) and the Adjective Checklist (ACL) (Siperstein, 1980; Siperstein \& Bak, 1977). 
Shared Activities Questionnaire (SAQ). The SAQ was developed to measure primary school children's attitudes towards a target child. It consists of 24 items that assess attitudes and behavioural intentions of TD children towards disabled peers. The items are split into three categories of interest: General Social (companionship with the target child at school) Academic (willingness to engage in academic activities with the target child) and Active Recreational (outside school activities with the target child).

Adjective Checklist (ACL). The ACL assesses cognitive attitudes towards the target person with disabilities and has been extensively used with primary school children. The ACL consists of 32 adjectives, 16 with positive (e.g., smart, happy) and 16 with negative (e.g., slow, unhappy) valence. Participants are required to circle as many words they wish to describe the target child.

Vignes, Godeau, Sentenac, Coley, Navarro, Grandjean \& Arnaud (2009) reviewed the use of the SAQ and the ACL among other 19 instruments developed to assess children's attitudes towards their peers with disabilities. The authors concluded that both instruments are valid instruments in terms of validity, reliability, test-retest reliability and internal consistency (reported Cronbach's alpha coefficients for the SAQ are typically over .80 and .81 to .91 for the ACL).

\subsubsection{Piloting Measurements}

Although the SAQ and the ACL have been extensively used and are standardised questionnaires they were piloted because they have been used for primary school children, whereas here they were administered to young adolescents. The pilot study was performed in five Year 7 and Year 8 classes in a mixed school in London. Children viewed the Powerpoint presentations and were administered the SAQ and the ACL. Based on pilot participant's feedback some activities as described by the SAQ were modified in order to be more age-appropriate. No recommendations for changes were provided in relation to the ACL. Additionally, an adjective in the ACL was changed from US terminology (original questionnaire) to the UK terminology (the adjective "neat" changed to be "cool").

\subsubsection{Vignettes and Powerpoint Presentation}

Three sets of vignettes were developed; one for the TD target and two for the AS target with either descriptive or combined information. The vignette of the TD target informed participants about the target's interests, such as that he liked computer games and football and highlighted similarities between the target and themselves (e.g., "John is about the same age as you"). The vignette with descriptive information regarding the target with AS provided the same information as above but also highlighted behavioural aspects and characteristics that are common among children and young adolescents with AS. For instance, participants were informed that the target child "spends most of his lunchtime and breaks on his own" or that the target child "does not always understand jokes". Regarding the target's interests, he was described to have similar interests as the TD target but to be more preoccupied. For example, similarly to the TD target participants were told that the target with AS likes football but that he likes it so much that he "can remember the results of every single match played by his favourite team". Finally, the vignette describing the AS target with combined information provided the same information as in the above two sets of vignettes but here there was a brief educational message about AS. That is, participants were told that the target child "has Asperger's syndrome, which means that he has difficulties talking to other people and understanding what they feel or think. Asperger syndrome is something that you are born with and it affects the way the brain works. People with Asperger syndrome can learn to do many of the things that other people can do, they just need more time and help". Additionally, participants provided with combined information about the target with AS were informed that some of the target's behaviour was due to his condition. For instance, they were informed that "like many people with Asperger syndrome [the target's child] wants to make more friends, but doesn't know how to". Particular care was waken for all the vignettes to be of the same length. The vignettes were read out by four young males. Two young undergraduate students pretended to be the target's friend and two adult males pretended to be the target's teacher. During the reading vignette process the voice was recorded. The vignettes were piloted with ASD-experienced practitioners in the NHS to ensure the accuracy of the passage attempting to describe an adolescent with AS.

To develop the Powerpoint presentation a series of pictures were taken of two different young boys (of the same age as the participants) performing daily activities in their homes (e.g., playing, studying, eating). One boy was selected to represent the TD target and one boy to represent the target with AS. The recorded voice matched the pictures of the two targets and participants viewed the targets on a Powerpoint presentation.

\subsection{Procedure}

Participants were tested in classroom settings. Each class viewed two Powerpoint presentations. First, the presentation of the TD target followed by the completion of the SAQ and the ACL and then the presentation of the 
target with AS with either descriptive or combined information again followed by the completion of the SAQ and the ACL. Prior to data collection participants were asked to sign consent. The participant's consent forms were collected before they were given the questionnaires and were kept separately in order to avoid subject identification. Each experimental session lasted approximately 25 minutes while a teacher was present throughout the sessions.

\subsection{Data Analysis Procedure}

To assess behavioural intentions towards the targets participants received three points for every "yes" response, two points for every "maybe" response and a one point for every "no" response. Thus, the maximum score a participant can get is 72 (a "Yes" response to all items) and the minimum score is 24 (a "No" response to all items). To assess attitudes towards the targets the total score of the ACL is calculated by subtracting the number of negative adjectives children choose from the total number of positive adjectives and adding a constant of 20 (Siperstein \& Bak, 1977). Scores can range from 4 to 36 , scores above 20 indicating more positive than negative attitudes. The scores were transferred to the statistical package for social sciences (SPSS) version 20. Initially, the analysis focus on the comparison of behavioural intentions and attitudes towards both targets by running mixed model analysis of variance (ANOVA) by including participant's gender, Year and source the person who delivered the information as the independent variables. Next, the analysis focus solely on attitudes and intentions towards the target with AS by running analysis of covariance (ANCOVA) were scores towards the TD target functioned as a covariate. In all post-hoc analyses, all p-values have been subjected to appropriate Bonferroni corrections for four comparisons. Thus, the new critical alpha level set is $\alpha_{c r i t}=.0125$.

\section{Results}

\subsection{Comparison of Participants' Attitudes and Behavioural Intentions towards the TD Target and the Target with AS}

The mean scores of participants' attitudes and behavioural intentions towards the target with AS and the TD target are presented in Table 1 and Table 2.

Table 1. Means SAQ and ACL Scores (standard deviations in parentheses) of Year 7 Participants for the TD and AS Target as a Function of information Type, Information Source and Participant' Gender

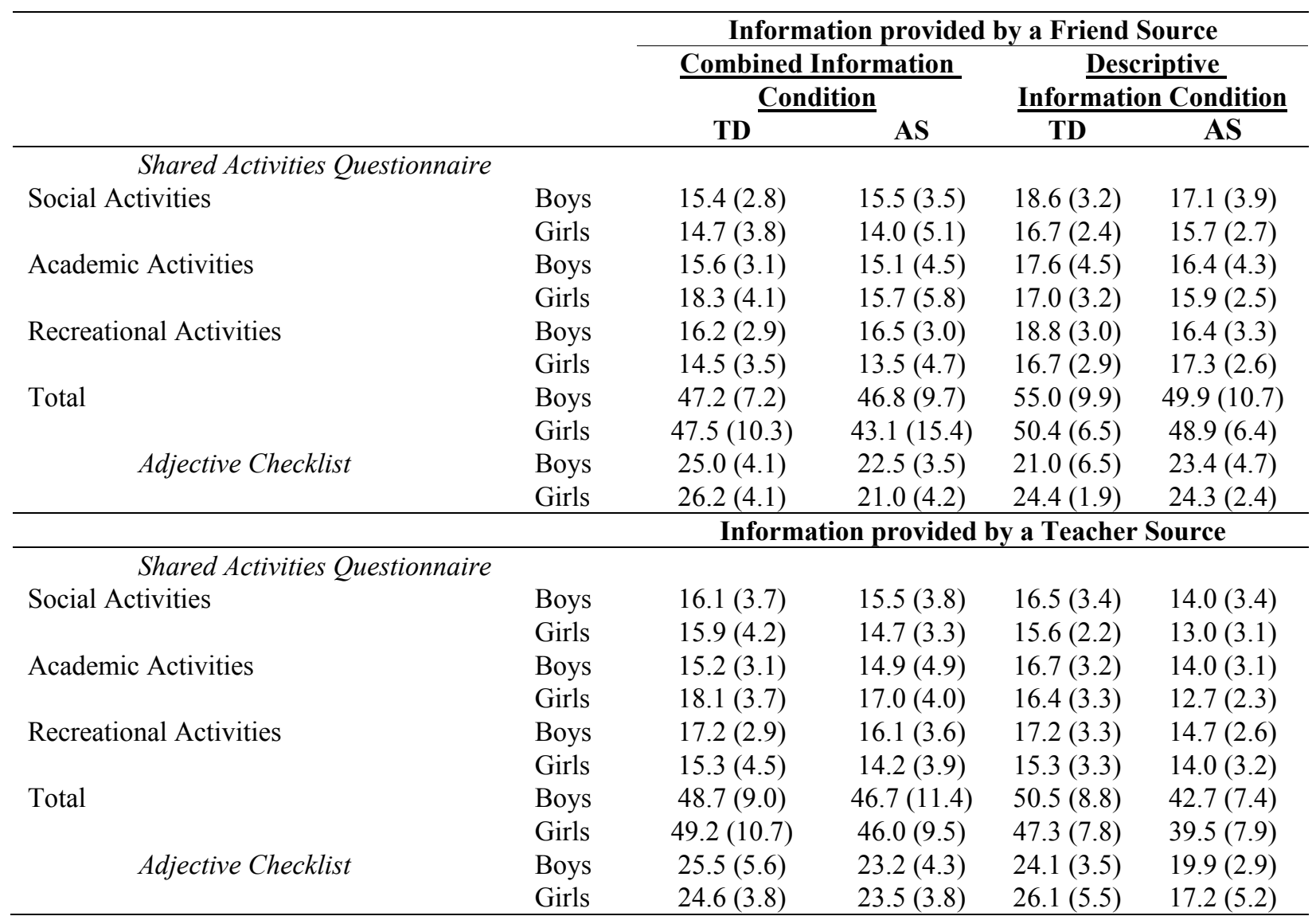


Table 2. Means SAQ and ACL Scores (standard deviations in parentheses) of Year 10 Participants for the TD and AS Target as a Function of Information Type, Information Source and Participant' Gender

\begin{tabular}{|c|c|c|c|c|c|}
\hline & & \multicolumn{4}{|c|}{ Information provided by a Friend Source } \\
\hline & & \multicolumn{2}{|c|}{$\frac{\text { Combined Information }}{\underline{\text { Condition }}}$} & \multicolumn{2}{|c|}{$\frac{\text { Descriptive Information }}{\underline{\text { Condition }}}$} \\
\hline & & TD & $\mathbf{A S}$ & TD & $\mathbf{A S}$ \\
\hline \multicolumn{6}{|l|}{ Shared Activities } \\
\hline \multicolumn{6}{|l|}{ Questionnaire } \\
\hline \multirow[t]{2}{*}{ Social Activities } & Boys & $14.1(2.2)$ & $10.7(2.1)$ & $15.0(3.3)$ & $15.6(3.2)$ \\
\hline & Girls & $14.9(4.5)$ & $16.0(4.4)$ & $18.1(3.7)$ & $17.4(5.0)$ \\
\hline \multirow[t]{2}{*}{ Academic Activities } & Boys & $12.5(2.5)$ & $10.7(2.8)$ & $14.3(3.5)$ & $16.3(4.1)$ \\
\hline & Girls & $16.8(4.3)$ & $16.3(4.4)$ & $17.1(5.5)$ & $18.2(5.8)$ \\
\hline \multirow[t]{2}{*}{ Recreational Activities } & Boys & $14.0(2.2)$ & $10.9(1.9)$ & $15.4(3.3)$ & $15.1(3.1)$ \\
\hline & Girls & $14.6(4.4)$ & $15.0(4.9)$ & $18.3(3.3)$ & $17.1(5.0)$ \\
\hline \multirow[t]{2}{*}{ Total } & Boys & $40.6(5.6)$ & $32.1(5.4)$ & $44.6(9.2)$ & $47.1(10.4)$ \\
\hline & Girls & $46.3(12.8)$ & $47.4(13.2)$ & $53.5(12.4)$ & $52.8(15.4)$ \\
\hline \multirow[t]{3}{*}{ Adjective Checklist } & Boys & $22.2(4.7)$ & $18.9(5.2)$ & $21.9(6.8)$ & $23.5(4.6)$ \\
\hline & Girls & $23.8(3.9)$ & $21.7(3.3)$ & $24.9(6.5)$ & $21.9(3.6)$ \\
\hline & & \multicolumn{4}{|c|}{ Information provided by a Teacher Source } \\
\hline \multicolumn{6}{|l|}{ Shared Activities } \\
\hline \multicolumn{6}{|l|}{ Questionnaire } \\
\hline \multirow[t]{2}{*}{ Social Activities } & Boys & $14.1(2.8)$ & $11.5(3.0)$ & $17.2(2.8)$ & $13.2(4.6)$ \\
\hline & Girls & $14.3(1.4)$ & $13.5(2.5)$ & $16.9(3.3)$ & $14.1(2.8)$ \\
\hline \multirow[t]{2}{*}{ Academic Activities } & Boys & $12.3(3.0)$ & $10.8(3.9)$ & $16.5(3.4)$ & $13.0(4.4)$ \\
\hline & Girls & $16.7(1.5)$ & $14.3(2.5)$ & $16.9(3.6)$ & $14.3(3.5)$ \\
\hline \multirow[t]{2}{*}{ Recreational Activities } & Boys & $14.4(3.7)$ & $12.3(3.6)$ & $17.2(3.2)$ & $13.2(5.3)$ \\
\hline & Girls & $15.0(3.2)$ & $12.7(2.8)$ & $15.2(3.4)$ & $13.0(2.8)$ \\
\hline \multirow[t]{2}{*}{ Total } & Boys & $40.9(8.3)$ & $34.7(9.6)$ & $50.8(8.5)$ & $39.4(14.0)$ \\
\hline & Girls & $46.0(5.4)$ & $41.2(7.1)$ & $49.0(9.2)$ & $41.4(8.3)$ \\
\hline \multirow[t]{2}{*}{ Adjective Checklist } & Boys & $24.5(4.4)$ & $22.7(5.1)$ & $25.0(2.1)$ & $21.7(2.9)$ \\
\hline & Girls & $26.1(1.8)$ & $23.2(3.7)$ & $25.0(2.1)$ & $21.4(2.4)$ \\
\hline
\end{tabular}

To compare participants' attitudes and behavioural intentions towards the TD target and the target with AS, a 2 (Gender: males vs. females) by 2 (Year: Year 7 vs. Year 10) by 2 (Source: teacher vs. friend) mixed model ANOVA was performed on TD and AS scores separately for each of the three dimensions of the SAQ (social, academic and recreational). The same procedure was performed to analyse the scores on the ACL. Information type was not included in this analysis as the presentation of the TD target was accompanied only by descriptive information.

For the SAQ Social domain a significant main effect of diagnosis was found with participants being more willing to engage in social activities with the TD target $(M=15.8)$ than with the target with AS $(M=14.4), F(1,171)=31.4$, $p<.001, n^{2}=.15$. A significant two-way interaction was found between diagnosis and source, $F(1,171)=11.7$, $p<.001, n^{2}=.06$. Paired sample t-tests revealed that when information was delivered by the hypothetical teacher, the TD target was rated significantly higher than the target with AS $\left[M=15.9\right.$ vs. $M=13.8, t(91)=6.90, p<.001<p_{\text {crit }}$ $=.012]$. However, there was no significant difference in the evaluation of the TD target and the target with AS when information was delivered by the hypothetical friend $(p=.20)$. A further independent sample t-test showed that the evaluation of the TD target was not affected by the source of information $\left(p=.90>p_{\text {crit }}=.012\right)$ but the evaluation of the target with AS was more favourable when the information was delivered by a friend than by a teacher source $\left[M=15.3\right.$ vs. $\left.M=13.8, t(177)=2.74, p=.007<p_{\text {crit }} .012\right]$.

For the Academic activities a significant main effect of diagnosis was found with scores being significantly higher for the TD target than for the target with AS $\left[M=16.1\right.$ vs. $\left.M=14.7, F(1,171)=26.1, p<.001, n^{2}=.13\right]$. A significant main effect of Year was also found with Year 7 participants scoring greater than Year 10 participants $[M=$ 16 vs. $\left.M=14.9, F(1,171)=4.61, p=.03, n^{2}=.02\right]$. Also, a main effect of gender was found with females scoring greater than males $\left[M=16.3\right.$ vs. $\left.M=14.5, F(1,171)=11.6, p=.001, n^{2}=.06\right]$. Finally, a significant two-way interaction was found between diagnosis and source, $F(1,171)=8.77, p=.003, n^{2}=.04$. As above, a paired sample 
t-test showed that information delivered by a teacher source resulted in greater evaluation for the TD target than for the target with AS $\left[M=16.0\right.$ vs. $\left.M=13.9, t(91)=6.28, p<.001<p_{\text {crit }}=.012\right]$. No significant difference was found when information was delivered by the hypothetical friend $\left(p=.23>p_{\text {crit }}=.012\right)$. Again, independent sample t-tests revealed that the evaluation of the TD target was not affected by the person who delivered the information $(p=.90>$ $p_{\text {crit }}=.012$ ) whereas the target with AS was rated more favourable when information delivered by the friend than by the teacher source $\left[M=15.6\right.$ vs. $\left.M=13.69, t(177)=2.58, p=.010<p_{\text {crit }}=.012\right]$.

The SAQ Recreational activities revealed a significant main effect of diagnosis with scores being higher for the TD target than for the target with AS $\left[M=15.8\right.$ vs. $\left.M=14.4, F(1,171)=32.5, p<.001, n^{2}=.16\right]$. A significant main effect of Year was also found with Year 7 participants scoring greater than Year 10 participants $[M=15.7$ vs. $M=$ $\left.14.5, F(1,171)=6.70, p=.010, n^{2}=.03\right]$. As before a two-way interaction was found between diagnosis and source, $F(1,171)=7.33, p=.007, n^{2}=.04$. Again, paired sample t-tests showed that information delivered by a friend resulted in no significant difference in the evaluation of the TD target and the target with $\mathrm{AS}\left(p=.03>p_{\text {crit }}=.012\right)$ whereas information delivered by the teacher source resulted in more favourable scores towards the TD target than the target with AS $\left[M=16\right.$ vs. $\left.M=14, t(91)=6.20, p<.001<p_{\text {crit }}=.012\right]$. Independent sample t-tests showed that the evaluation of the TD target was not affected by the source of information $\left(p=.90>p_{\text {crit }}=.012\right)$ whereas the target with AS received greater evaluation when information was delivered by the friend than by the teacher source $\left[M=15.6\right.$ vs. $\left.M=14, t(177)=2.58, p=.010<p_{\text {crit }}=.012\right]$.

For the ACL scores again a significant effect of diagnosis was found with more positive adjectives attributed to the TD target than to the target with AS, $\left[M=24.4\right.$ vs. $\left.M=21.8, F(1,171)=40.6, p<.001, n^{2}=.19\right]$. A significant two-way interaction was also found between diagnosis and source, $F(1,171)=5.56, p=.019, n^{2}=.03$. Paired sample t-tests showed that the TD target was rated significantly greater than the target with AS regardless of whether information was delivered by a friend $\left[M=23.6\right.$ vs. $\left.M=22.1, t(86)=2.52, p=.013 \approx p_{\text {crit }}=.012\right]$ or by a teacher $\left[M=25.1\right.$ vs. $\left.M=21.6, \mathrm{t}(91)=6.51, p<.001<p_{\text {crit }}=.012\right]$ source. Independent sample t-tests revealed that neither the evaluation of the TD target nor the evaluation of the target with AS was affected by the source of information ( $p=.06$ and $p=.38$ respectively $>p_{\text {crit }}=.012$ ).

\subsection{Attitudes and Behavioural Intentions towards the Target with AS}

Participants' attitudes and behavioural intentions towards the target with AS were assessed by having the equivalent scores for the TD target as a covariate in order to examine for any potential effects that the presentation of the TD target may have exerted. A 2 (gender: males vs. females) by 2 (Year: Year 7 vs. Year 10) by 2 (Information type: combined vs. descriptive information) by 2 (source: teacher vs. friend) Analysis of Covariance (ANCOVAs) were performed. Throughout the whole analysis the covariate was found to be statistically significant $(p<.001)$ indicating that the presentation of the TD target had an effect upon evaluation of the target with AS. Therefore, the assumptions of ANCOVA were met. As before, the three SAQ subscales and the ACL were analysed separately.

For the Social activities a significant main effect of source was found with scores being higher when information was delivered by a friend than by a teacher source $\left(M=15.2\right.$ vs. $\left.M=13.7, F(1,162)=11.4, p=.001, n^{2}=.06\right]$. Similarly, a friend rather than a teacher source triggered greater scores on the SAQ Academic domain $[M=15.5$ vs. $M=13.8, F(1$, $\left.162)=10.2, p=.002, n^{2}=.06\right]$. Also, a significant two-way interaction was found between information type and source, $\left.F(1,162)=9.89, p=.002, n^{2}=.05\right]$. Continuing to use the Academic scores for the TD target as a covariate, a further ANCOVA analysis showed that descriptive information was more effective when it was delivered by a friend rather than by a teacher source $\left[M=16.7\right.$ vs. $\left.M=13.5, F(1,82)=19.5, p<.001<p_{\text {crit }}=.012\right]$. A further ANCOVA showed that the teacher source was more effective when accompanied with combined rather than with descriptive information $\left[M=14.7\right.$ vs. $\left.M=13.1, F(1,89)=5.86, p=.018 \approx p_{\text {crit }}=.012\right]$. Finally, the Recreational domain analysis revealed a significant main effect of source with the friend compared to the teacher source resulting in greater evaluation, $\left[M=15.1\right.$ vs. $\left.M=13.8, F(1,162)=8.37, p=.004, n^{2}=.04\right]$. A significant main effect of Year was also found with Year 7 participants being more positive than Year 10 participants, $[M=15$ vs. $M=14, F(1,162)=5.88$, $\left.p=.01, n^{2}=.03\right]$.

For the ACL scores a significant interaction was found between information type and source, $F(1,162)=23.5$, $\left.p<.001, n^{2}=.12\right]$. Continuing to use the ACL scores for the TD target as a covariate, one-ways ANCOVA's showed that the friend source resulted in significantly higher scores with descriptive than with combined information, $[M=$ 23.4 vs. $\left.M=24.1, F(1,84)=7.83, p=.006<p_{\text {crit }}=.012\right]$. The teacher source, however, resulted in higher scores with combined than with descriptive information, $\left[M=23.1\right.$ vs. $\left.M=20.1, F(1,89)=13.08, p<.001<p_{\text {crit }}=.012\right]$. Further ANCOVA's showed that combined information was not affected by the source of information $\left(p=.05>p_{\text {crit }}=.012\right.$ ) whereas descriptive information resulted in significantly higher scores when it was delivered by a friend than by a 
teacher source, $\left[M=23.3\right.$ vs. $\left.M=20.1, F(1,82)=13.61, p<.001<p_{\text {crit }}=.012\right]$.

\subsection{Summary of Main Findings}

Overall, the analysis showed that TD young adolescents held more positive attitudes and behavioural intentions towards a TD target than towards a target presented as having AS. When the analysis focused exclusively on attitudes and intentions towards the target with AS then it was found that a similar compared to a dissimilar other (i.e., a friend rather than a teacher source) exerted a more positive impact upon participants. The addition of a brief educational message (combined information), however, did not trigger more positive intentions and attitudes.

\section{Discussion}

\subsection{Comparing Attitudes and Intentions towards the TD Target and the Target with AS}

This study initially compared the attitudes and intentions of TD young adolescents towards a hypothetical TD target and towards a target with AS. In line with the literature (e.g., Campbell et al., 2004; Swaim \& Morgan, 2001) this study revealed more positive attitudes and behavioural intentions towards a hypothetical TD target than towards a target with AS. Nevertheless, it is noteworthy that a close inspection of the means indicates that participants showed some positive intentions and attitudes towards the target with AS. That is, the scores were in the mid-range, suggesting that participants had at least some willingness to perform certain activities with the target with AS. This can also be speculated by the small effect sizes found throughout the analysis.

The analysis of this comparison revealed a repeated interaction between the source of information and the target's diagnosis. This interaction showed that information by a friend source resulted in an equal degree of willingness to engage in all areas of activities with both targets. In contrast, when the targets were introduced by the teacher, then participants showed more positive behavioural intentions towards the TD target than towards the target with AS. This is an important finding because it shows that information delivered by a friend resulted in less discrimination towards a child with AS compared to when the same information was delivered by a teacher. Berndt (1979) and Hay, Payne and Chadwick (2004) suggested that young adolescents are highly affected by their peers rather by other sources (e.g., parents and teachers) due to an intense need for belonging and to be accepted by similar others. This does not appear surprising given that young adolescents spend twice as much time with their peers (in addition to the time they spend together in class) compared to the time they spend with their parents and other adults (Parke, Clarke-Stewart, 2010). Thus, in relation to the above interaction it might be the case that observing a similar other (i.e., the target's friend) acting in a particular way (befriend a peer with AS) resulted in a greater effect than a dissimilar other (i.e., the target's teacher).

\subsection{Effect of Information Type and Source of Information on Attitudes and Intentions towards the Target with AS}

Regarding the efficacy of descriptive and combined information the results revealed a no significant overall advantage for either information type. Contrary to expectations, the addition of a medical explanation (combined information) about the target with AS did not improve participants' attitudes and intentions. This finding is in line with Swaim and Morgan's (2001) but in contrast to Campbell et al.'s (2004) study. Laws and Kelly (2005) hold the view that it is a mistake to believe that by explaining a condition to children their attitudes can change. It is not very likely that a brief educational message will change views and beliefs that have been developed over long periods of time. Rather, multi-session interventions are more likely to result in longer-lasting effects than single-session interventions.

In terms of the source of information a significant main effect of source was found throughout the analysis of participants' intentions (but not attitudes) towards the target with AS. In particular a friend rather than a teacher was more effective in improving participants' social, academic and recreational intentions. This finding suggest that participants showed greater intentions to engage in all areas of activities with the target with AS when the target was introduced by a friend than by a teacher. This is of particular importance as it can have practical implications that can be applied in real life settings when a new child with AS is about to attend a mainstream school. Of interest is the interaction between the source of information and the information type that was found both on intentions and attitudes towards the target with AS. According to this interaction descriptive information triggered more positive intentions and attitudes when it was delivered by the target's friend rather than by his teacher. Combined information, on the other hand, was equally effective on participant's intentions and attitudes regardless of the source of information. This can be interpreted in the following way. A similar other (the friend source) was an effective source to introduce the target with no reference to disability (descriptive information). However, when there was a reference to disability (combined information) then a teacher appeared to be a more effective source. That is, participants' 
decision about whether to befriend a child with a disability and the formation of their attitudes might be more affected by a source perceived as more rather than less knowledgeable, i.e., a teacher rather than a friend source.

\subsection{Attitudes and Behavioural Intentions towards the Target with AS as a Factor of Participant's Age and Gender}

An effect of age was found for recreational intentions with younger participants scoring greater towards the target with AS compared to older ones. The literature suggest that younger compared to older children are more positive towards peers with autism (Campbell et al., 2004) and with other disabilities (e.g.,Ryan, 1981). However, this study showed that younger compared to older participants were more positive not only towards the target with AS but also towards the TD target. It might be the case that younger compared to older children are in general more willing to welcome new peers regardless of whether they have a disability or not.

Interestingly, no gender effect was found on attitudes and intentions towards the target with AS. This finding is not in line with the literature, which has demonstrated a robust effect of gender differences, with girls compared to boys responding more favourably towards peers with various conditions (e.g., Panek \& Smith, 2005) and autism (Campbell et al., 2004). A possible reason of the lack of any gender difference might have been due to the target being male. The literature has provided evidence that children are more positive towards peers with disabilities of their own rather than of the opposite gender (e.g., Bell \& Morgan, 2000). This is likely to have been the case here given that the target was described in a way that is assumed to have matched more the interests of boys than of girls (e.g., playing football). Girl participants may have responded more positively if the target was of their own gender, as they might have been more willing to befriend a girl than a boy.

\subsection{Study Limitations}

The results of this research, however, must be understood within the context of limitations produced by the current design. One of the primary goals of this work was to identify whether descriptive or combined information triggers more positive attitudes and intentions towards the target with AS. However, a design weakness might have affected the results regarding this variable. Participants that were provided with descriptive information were only given information about the target's atypical behaviour but were not told that he had an AS diagnosis. Thus, participants in this condition might have perceived the target as a peer with somewhat peculiar behaviour rather than as a peer with a disability. Participants in the combined information condition, however, were informed that the target had an AS diagnosis. Thus, the two information types in this study may be criticised as not being equivalent, as one condition labelled the target while the other did not. As labelling may lead to stigmatised beliefs, the fact that provision of information was confounded with use of the diagnostic label is problematic for the interpretation of the results. This is undoubtedly a limitation of this study which required further exploration of the efficacy of the two information types.

Additionally, order effects might account for the lower ratings of the target with AS compared to the TD target. Participants watched the presentation about the TD target always at the beginning of each experimental session followed by the presentation of the target with AS. However participants' greater scores for the TD target than for the target with AS is in line with the literature on attitudes and intentions towards peers with autism (e.g., Campbell et al., 2004; Swaim \& Morgan, 2001) and other disabilities (e.g., Friedrich, Morgan \& Devine, 1996). This make order effects not a particularly likely factor to have influenced the scores towards the target with AS.

A further limitation of the design is that the pictures representing the TD target and the target with AS were not piloted in relation to perceived attractiveness. It is likely that participant's evaluation of the targets was affected by the physical appearance of the targets rather than the description of the vignettes. A great deal of research has shown that people who are perceived to be more attractive rather than less attractive are rated more positively (e.g., Bornstein \& D' Augostino, 1992) and are more likely to be befriended by others (Sprecher, 1998). Thus, it is important for future studies in this area to match the pictures of the targets in terms of attractiveness by, for example, a pilot study before the main study.

A final limitation of this study could have been that the ethos of the school that the study took place is highly inclusive and particularly ASD-friendly. Thus, it is likely that participants were familiar with ASD either though students on the spectrum educated at the school or through class discussions. Given that the school is ASD friendly, one would expect that the teachers are also positive towards students on the spectrum. This in turn, may also have affected participants' responses given that studies have shown that teachers' attitudes towards peers with disabilities can significantly affect TD students' attitudes towards those peers (e.g., Ohan, Visser, Strain \& Allen, 2011). Therefore, it is not known whether the results of this study can be generalised to other students who have been educated in other environments. 


\section{Conclusion}

Despite limitations, this study can be considered as having made a significant contribution to the literature, as there was a gap regarding the attitudes and intentions of TD adolescents towards peers with AS. Also, this study showed that young adolescent's intentions and attitudes towards a peer with AS are highly influenced by a similar-other. Thus, it is suggested that future research should seek to evaluate the external validity of these findings by evaluating the effect of a similar-other introducing a peer with AS on attitudes and intentions under actual settings.

\section{References}

Adreon, D., \& Stella, J. (2001). Transition to middle and high school. Intervention in School and Clinic, 36(5), 266-271. http://dx.doi.org/10.1177/105345120103600502

Asperger, H. (1991). Autistic psychopathy in childhood. In U. Frith (Ed.), Autism and Asperger syndrome (pp. 37-92). Cambridge, UK: Cambridge University Press. http://dx.doi.org/10.1017/CBO9780511526770.002

Attwood, T. (2003). Navigating social and emotional pathways of autism. Sydney: Southern Sydney Therapy Centre.

Attwood, T. (2006). The Complete Guide to Asperger's Syndrome. London: Jessica Kingsley Publishers.

Bauminger, N., Solomon, M., Aviezer, A., Heung, K., Brown, J., \& Rogers, S. (2008). Friendship in high-functioning children with autism spectrum disorder: Mixed and non-mixed dyads. Journal of Autism and Developmental Disorders, 38(7), 1211-1229. http://dx.doi.org/10.1007/s10803-007-0501-2

Berndt, T. J. (1979). Developmental changes in conformity to peers and parents. Developmental Psychology, 15(6), 608-616. http://dx.doi.org/10.1037/0012-1649.15.6.608

Bell, S. K., \& Morgan, S. B. (2000). Children's attitudes and behavioral intentions toward a peer presented as obese: Does a medical explanation for the obesity make a difference? Journal of Pediatric Psychology, 25(3), 137-145. http://dx.doi.org/10.1093/jpepsy/25.3.137

Bornstein, R. F., \& D' Augustino, P. R. (1992). Stimulus recognition and the mere exposure effect. Journal of Personality and Social Psychology, 63(4), 545-552. http://dx.doi.org/10.1037/0022-3514.63.4.545

Campbell, J. M. (2006). Changing children's attitudes toward autism: A process of persuasive communication. Journal of Developmental and Physical Disabilities, $18(3), \quad 251-272$. http://dx.doi.org/10.1007/s10882-006-9015-7

Campbell, J. M. (2007). Middle school students' response to the self-introduction of a student with autism. Remedial and Special Education, 28(3), 163-173. http://dx.doi.org/10.1177/07419325070280030501

Campbell, J. M., Ferguson, J. E., Herzinger, C. V., Jackson, J. N., \& Marino, C. A. (2004). Combined descriptive and explanatory information improves peers' perceptions of autism. Research in Developmental Disabilities, 25(4), 321-339. http://dx.doi.org/10.1016/j.ridd.2004.01.005

Church, C., Alisanski, S., \& Amanullah, S. (2000). The social, behavioral, and academic experiences of children with Asperger syndrome. Focus on Autism and Other Developmental Disabilities, 15(1), 12-20. http://dx.doi.org/10.1177/108835760001500102

Ehlers, S., \& Gillberg, C. (1994). The epidemiology of Asperger syndrome. A total population study. Journal of Child Psychology and Psychiatry, 34(8), 1327-1350. http://dx.doi.org/10.1111/j.1469-7610.1993.tb02094.x

Friedrich, S., Morgan, S. B., \& Devine, C. (1996). Children's attitudes and behavioral intentions toward a peer with Tourette syndrome. Journal of Pediatric Psychology, 21(3), 307-319. http://dx.doi.org/10.1093/jpepsy/21.3.307

Hay, D. F., Payne, A., \& Chadwick, A. (2004). Peer relations in childhood. Journal of Child Psychology and Psychiatry, 45(1), 84-108. http://dx.doi.org/10.1046/j.0021-9630.2003.00308.x

Heider, F. (1958). The psychology of interpersonal relations. Erblaum, Hillsdale, NJ. http://dx.doi.org/10.1037/10628-000

Humphrey, N., \& Lewis, S. (2008). Make me normal: the views and experiences of pupils on the autistic spectrum in mainstream secondary schools. Autism: The International Journal of Research and Practice, 12(1), 23-46. http://dx.doi.org/10.1177/1362361307085267

Jones, E. E., Farina, A., Hastorf, A. H., Marcus, H., Miller, D. T., \& Scott, R. A. (1984). Social stigma: The psychology of marked relationships. New York: W. H. Freeman. 
Kasari, C., Locke, J., Gulsrud, A., \& Rotheram-Fuller, E. (2011). Social networks and friendships at school: comparing children with and without ASD. Journal of Autism and Developmental Disorders, 41(5), 533-544. http://dx.doi.org/10.1007/s10803-010-1076-x

Klin, A., \& Volkmar, F.R. (1995). Autism and the pervasive developmental disorders. Child and Psychiatric Clinics of North America, 4(3), 617-630.

Konza, D. (2005). Secondary school success for students with Asperger's syndrome. Australian Journal of Special Education, 29(2), 128-139. http://dx.doi.org/10.1080/1030011050290205

Lamarine, R. J. (2001). Asperger syndrome: Advice for school personnel. Preventing School Failure, 45(4), 148-152. http://dx.doi.org/10.1080/10459880109603329

Laws, G., \& Kelly, E. (2005). The attitudes and friendship intentions of children in United Kingdom mainstream schools towards peers with physical or intellectual disabilities. International Journal of Disability, Development and Education, 52(2), 79-99. http://dx.doi.org/10.1080/10349120500086298

Linn, A., \& Myles, B. S. (2004). Asperger syndrome and six strategies for success. Beyond Behaviour, 14, 3-9.

Marks, S. U., Schrader, C., Longaker, T., \& Levine, M. (2000). Portraits of three adolescent students With Asperger's syndrome: Personal stories and how they can inform practice. Research and Practice for Persons with Severe Disabilities, 25(1), 3-17. http://dx.doi.org/10.2511/rpsd.25.1.3

Morton, J. F., \& Campbell, J. M. (2008). Information source affects peers' initial attitudes toward autism. Research in Developmental Disabilities, 29(3), 189-201. http://dx.doi.org/10.1016/j.ridd.2007.02.006

Morgan, S. B., Walker, M., Bieberich, A., \& Bell, S. (1996). The shared activities questionnaire. Unpublished manuscript, University of Memphis, Memphis, TN.

Nabors, L. A., \& Larson, E. R. (2002). The effects of brief interventions on children's playmate preferences for a child sitting in a wheelchair. Journal of Developmental and Physical Disabilities, 14(4), 403-413. http://dx.doi.org/10.1023/A:1020339004125

Ohan, J. L., Visser, T. A. W., Strain, M. C., \& Allen, L. (2011). Teachers' and education students' perceptions of and reactions to children with and without the diagnostic label "ADHD". Journal of School Psychology, 49(1), 81-105. http://dx.doi.org/10.1016/j.jsp.2010.10.001

Panek, P. E., \& Jungers, M. K. (2008). Effects of age, gender, and causality on perceptions of persons with mental retardation. Research in Developmental Disabilities, 29(2), 125-132. http://dx.doi.org/10.1016/j.ridd.2007.01.002

Panek, P. E., \& Smith, J. L. (2005). Assessment of terms to describe mental retardation. Research in Developmental Disabilities, 26(6), 565-576. http://dx.doi.org/10.1016/j.ridd.2004.11.009

Parke, R. D., \& Clarke-Stewart, A. (2010). Social development. New York, NY: Wiley.

Ryan, K. M. (1981). Developmental differences in reactions to the physically disabled. Human Development, 24(4), 240-256. http://dx.doi.org/10.1159/000272685

Safran, J. S. (2002). Supporting students with Asperger syndrome in general education. Teaching Exceptional Children, 34, 60-66.

Shtayermman, O. (2007). Peer victimization in adolescents and young adults diagnosed with Asperger's syndrome: A link to depressive symptomatology, anxiety symptomatolgoy and suicidal ideation. Issues in Comprehensive Pediatric Nursing, 30(3), 87-107. http://dx.doi.org/10.1080/01460860701525089

Sigelman, C. K. (1991). The effect of causal information on peer perceptions of children with physical problems. Journal of Applied Developmental Psychology, $12(2), \quad$ 237-253. http://dx.doi.org/10.1016/0193-3973(91)90014-U

Siperstein, G. N. (1980). Development of the Adjective Checklist: An instrument for measuring children's attitudes toward the handicapped. Unpublished manuscript, University of Massachusetts, Boston.

Siperstein, G. N., \& Bak, J. J. (1977). Instruments to measure children's attitudes toward the handicapped: Adjective checklist and activity preference list. Unpublished manuscript, University of Massachusetts, Boston.

Swaim, K. F., \& Morgan, S. B. (2001). Children's attitudes and behavioural intentions toward a peer with autistic behaviours: Does a brief educational intervention have an effect? Journal of Autism and Developmental 
Disorders, 31(2), 195-205. http://dx.doi.org/10.1023/A:1010703316365

Taylor, S. E., Peplau, L. A., \& Sears, D. O. (2003). Social psychology (11th ed.). Upper Saddle River, NJ: Prentice Hal.

Vignes, C., Godeau, E., Sentenac, M., Coley, N., Navarro, F., Grandjean, H., \& Arnaud, C. (2009). Determinants of students' attitudes towards peers with disabilities. Developmental Medicine \& Child Neurology, 51(6), 473-479. http://dx.doi.org/10.1111/j.1469-8749.2009.03283.x

Wainscot, J., Naylor, P., Sutcliffe, P., Tantam, D., \& Williams, J. (2008). Relationship with peers and the school environment of mainstream secondary school pupils with Asperger Syndrome (high-functioning autism): A case-control study. International Journal of Psychology and Psychological Therapy, 8(1), 25-38.

Weiner, B. (1980). A cognitive attribution-emotion-action model of motivation behaviour: An analysis of judgments of helpgiving. Journal of Personality and Social Psychology, 39(2), 186-200. http://dx.doi.org/10.1037/0022-3514.39.2.186

Weiner, B., Perry, R. P., \& Magnusson, J. (1988). An attributional analysis of reactions to stigmas. Journal of Personality and Social Psychology, 55(5), 738-748. http://dx.doi.org/10.1037/0022-3514.55.5.738

Williams, K. (2001). Understanding the student with Asperger syndrome: Guidelines for teachers. Intervention in School and Clinic, 36(5), 287-292. http://dx.doi.org/10.1177/105345120103600505 